\title{
Innovación docente aplicada a la enseñanza de la Historia del Arte
}

\section{Applying teaching innovation to History of Art learning}

DiANA OliVARES MaRTínez

ORCID: http://orcid.org/0000-0001-8159-7213

Universidad de Sevilla

Departamento de Historia del Arte

dolivares@us.es

Fecha de recepción: 19-11-2019

Fecha de aceptación:

DOI: http://dx.doi.org/10.12795/9788447221912.106

Pp.: 2374-2395 


\section{Resumen}

Esta publicación presenta una experiencia de mejora llevada a cabo en la asignatura Historia de la Arquitectura y el arte del Grado en Geografía y Gestión del Territorio. La propuesta radica en un cambio del modelo metodológico de enseñanza habitual, basado en la clase magistral de carácter teórico, hacia un nuevo modelo desarrollado a partir del aprendizaje por preguntas y/o problemas que favorece la participación del alumno.

Palabras clave: Historia del Arte, Grado en Geografía y Ordenación del Territorio, docencia universitaria, experimentación docente universitaria.

\section{Abstract}

This paper shows an improvement experience carried out in the subject Historia de la Arquitectura y el arte from the Degree in Geografia y Gestion del Territorio. The proposal is based on a change in the usual methodological teaching pattern, which implied a theoretical master class, looking forward to a new pattern developed from learning by questions or problems that contributes to the student participation.

Keywords: History of Art, Degree in Geografía y Ordenación del Territorio, university teaching, experimentation on university teaching.

Jornadas de Formación e Innovación Docente del Profesorado | № 2 (2019) Esta obra se distribuye con la licencia Creative Commons Reconocimiento-NoComercial-SinObraDerivada 4.0 Internacional (CC BY-NC-ND 4.0.) 


\section{Descripción del contexto:}

El Ciclo de Mejora en el aula (en adelante, CIMA) se ha aplicado en la asignatura de primer curso Historia de la arquitectura y el arte del Grado en Geografia y Gestión del Territorio. Se trata de una asignatura de Formación Básica que consta de 6 créditos teórico-prácticos y se imparte durante dos días en semana de 18 a 19:30. Si bien es un grupo poco numeroso con 25 estudiantes matriculados, la poca regularidad en la asistencia de los estudiantes a clase, motivada por ser la última asignatura del día, ha generado ciertos desajustes en la aplicación del CIMA. También ha dificultado su desarrollo la incorporación constante de nuevos alumnos matriculados al Grado durante todo el mes de octubre. El principal reto de esta asignatura, que consiste en una introducción a la Historia del Arte, es despertar el interés de los estudiantes por una materia generalmente percibida como ajena por los propios alumnos -con escasos conocimientos sobre la misma- con relación al resto de plan de estudios de su Grado.

\section{Diseño previo del CIMA}

El CIMA fue diseñado para aplicarse entre los días 24 de octubre y 13 de noviembre de 2019. Debido a que las clases tienen una duración de 90 minutos, planifiqué seis sesiones de aplicación hasta sumar un total de 9 horas. En ese tiempo pretendí abordar los siguientes temas: Roma (tema 4), Arte paleocristiano y bizantino (tema 5) y Arte prerrománico y románico (tema 6). La pregunta que pretendía dotar de unidad a estos contenidos del CIMA, que se plantearía a los estudiantes en la primera sesión, fue la siguiente: ¿qué relación hay entre el arte romano y el románico?

Jornadas de Formación e Innovación Docente del Profesorado | № 2 (2019) Esta obra se distribuye con la licencia Creative Commons Reconocimiento-NoComercial-SinObraDerivada Internacional (CC BY-NC-ND 4.0.) 


\section{Mapa de contenidos}

Como parte del diseño del CIMA, elaboré un mapa de contenidos organizado en torno a tres grandes preguntas o problemas en el que predominan los contenidos conceptuales, si bien también se indican los procedimientos intelectuales y los contenidos relativos a actitudes o valores. Su realización me ha permitido reflexionar sobre cuáles eran los contenidos esenciales y también cuál era la relación que podía establecerse entre ellos.

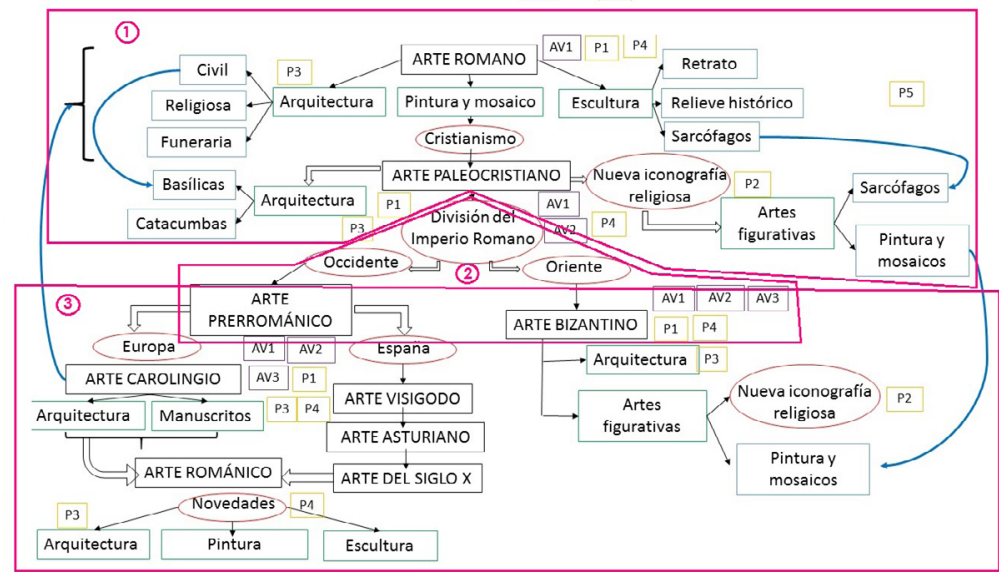

Procedimientos Intelectuales:

P1: Realizar el análisis de obras correctamente

P2: Interpretar motivos de iconografia religiosa

P3: Leer una planta de un edificio

P4: Identificar novedades y cambios respecto al periodo anterior

Actitudes / valores:

AV1: Conservación del Patrimonio

AV2: Valorar estética de lo no-bello

AV3: Contacto / transmisión entre culturas

P5: Utilizar el vocabulario específico

\footnotetext{
Preguntas/problemas

$1-$ ¿Cómo cambió el Cristianismo el arte romano?

2 - ¿Cómo influyó en el arte la división del Imperio romano?

3 - ¿Qué elementos han perdurado desde Roma en el Prerrománico y el Bizantino?
}

Figura 1. Mapa de contenidos

\section{Modelo metodológico posible y secuencia de actividades}

Pese a que inicialmente pensé que el modelo metodológico posible más apropiado para mí como docente y para alumnos con pocos conocimientos iniciales sería el basado en la teoría y su aplicación en la práctica, tras las 
primeras sesiones del CGDU quise plantearme poner en práctica un modelo basado en la reelaboración de las ideas de los estudiantes. De manera inconsciente, siempre ha sido habitual en mi práctica docente hacer preguntas a los alumnos para captar su atención y asegurarme de que comprenden ciertas cuestiones. Por ello escogí este modelo metodológico basado en la idea de que el aprendizaje es el resultado de la interacción entre los significados que están en la mente del que aprende y las informaciones que le llegan del exterior (Alba y Porlán, 40-41). En esencia, consiste en activar el interés del alumno a partir de una cuestión inicial que les implica en el proceso de aprendizaje. Posteriormente, se confrontarán sus ideas iniciales con nuevas informaciones que pondrán en evidencia sus limitaciones para resolverlas, dirigiendo al estudiante hacia una reelaboración de sus ideas para completarlas con explicaciones teóricas y actividades prácticas hasta alcanzar una conclusión final.

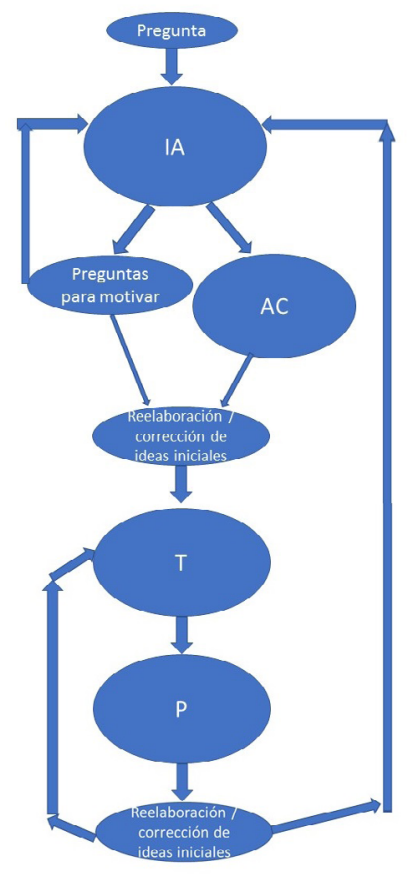

Imagen 2: Modelo metodológico.

(IA: Ideas del alumno - AC: Actividad de contraste - T: Teoría - P: Práctica)

Jornadas de Formación e Innovación Docente del Profesorado | № 2 (2019) Esta obra se distribuye con la licencia Creative Commons Reconocimiento-NoComercial-SinObraDerivada 
En la siguiente tabla se recoge la secuencia de actividades de este CIMA.

Tabla 1: Secuencia de actividades del ciclo de mejora

\begin{tabular}{|c|c|c|c|}
\hline \multicolumn{4}{|c|}{ SESIÓN 1. Arte romano $(24 / 10)$ - $90 \mathrm{~min}}$. \\
\hline $\begin{array}{l}\text { Modelo } \\
\text { metodológico } \\
\text { posible }\end{array}$ & Actividad & Descripción & $\begin{array}{c}\text { Tiempo } \\
\text { (min.) }\end{array}$ \\
\hline Pregunta & $\begin{array}{c}1 \\
\text { Introducción } \\
\text { al CIMA }\end{array}$ & $\begin{array}{l}\text { Planteo una pregunta inicial para } \\
\text { presentar el CIMA. ¿Qué relación hay } \\
\text { entre el arte romano y el románico? }\end{array}$ & 2 \\
\hline $\begin{array}{l}\text { Ideas de los } \\
\text { alumnos }\end{array}$ & $\begin{array}{c}2 \\
\text { Lluvia de } \\
\text { ideas sobre el } \\
\text { contenido del } \\
\text { CIMA }\end{array}$ & $\begin{array}{l}\text { Tras la pregunta, se abre un turno de } \\
\text { lluvia de ideas con el objetivo de que los } \\
\text { alumnos piensen por sí mismos tratando } \\
\text { de dar respuesta al interrogante } \\
\text { mediante sus conocimientos de cultura } \\
\text { general y mediante la lógica. Si no } \\
\text { surgen cuestiones, intentaré dar fluidez } \\
\text { a la actividad mediante preguntas } \\
\text { encadenadas, como, por ejemplo: ¿qué } \\
\text { obras conocéis de arte romano? ¿y de } \\
\text { románico? ¿qué tipo de arcos utilizan } \\
\text { esas obras? Como apoyo, también } \\
\text { llevaré dos imágenes que contrasten, } \\
\text { una de arte romano y otra de arte } \\
\text { románico. } \\
\text { Iré apuntando en la pizarra las ideas } \\
\text { más importantes y haré una foto a la } \\
\text { pizarra para proyectarla al final del } \\
\text { CIMA. }\end{array}$ & 10 \\
\hline \multicolumn{4}{|c|}{ PREGUNTA / PROBLEMA № 1: ¿Cómo cambió el Cristianismo el arte romano? } \\
\hline $\begin{array}{l}\text { Ideas de los } \\
\text { alumnos }\end{array}$ & $\begin{array}{l}3 \\
\text { Introducción } \\
\text { al arte } \\
\text { romano }\end{array}$ & $\begin{array}{l}\text { Pregunto: ¿qué sabemos del arte } \\
\text { romano? En conexión con la pregunta } \\
\text { anterior, haremos una breve lluvia de } \\
\text { ideas, con el objetivo de centrarnos en } \\
\text { el período y sacar a relucir nombres } \\
\text { de personajes importantes, ciudades o } \\
\text { ejemplos de obras de arte que puedan } \\
\text { conocer previamente. }\end{array}$ & 5 \\
\hline
\end{tabular}

Jornadas de Formación e Innovación Docente del Profesorado | № 2 (2019) Esta obra se distribuye con la licencia Creative Commons Reconocimiento-NoComercial-SinObraDerivada Internacional (CC BY-NC-ND 4.0.) 


\begin{tabular}{|c|c|c|c|}
\hline $\begin{array}{l}\text { Actividad de } \\
\text { contraste }\end{array}$ & $\begin{array}{c}4 \\
\text { Video sobre } \\
\text { el Imperio } \\
\text { romano }\end{array}$ & $\begin{array}{l}\text { Tras las ideas de los alumnos, planteo } \\
\text { el visionado del vídeo: El Imperio } \\
\text { romano en } 10 \text { minutos } \\
\text { (https://www.youtube.com/ } \\
\text { watch?v=UF_yHrFP1Ls) } \\
\text { ya que es un modo entretenido y rápido } \\
\text { de abordar el amplio contexto histórico } \\
\text { al que nos enfrentamos. El objetivo es } \\
\text { que los alumnos confirmen las hipótesis } \\
\text { acertadas y, además, que rellenen las } \\
\text { lagunas existentes. }\end{array}$ & 13 \\
\hline $\begin{array}{l}\text { Reelaboración } \\
\text { / corrección de } \\
\text { ideas iniciales }\end{array}$ & 5.Conclusión & $\begin{array}{l}\text { Concluyo las actividades } 3 \text { y } 4 \text { poniendo } \\
\text { en relación sus respuestas con lo } \\
\text { visto en el vídeo y haciendo hincapié } \\
\text { sobre aquellas cuestiones de mayor } \\
\text { relevancia. }\end{array}$ & 5 \\
\hline Teoría & $\begin{array}{c}6 \\
\text { Explicación } \\
\text { teórica }\end{array}$ & $\begin{array}{l}\text { Realizo una explicación teórica sobre } \\
\text { los orígenes del arte romano en el } \\
\text { etrusco y comienzo la arquitectura } \\
\text { románica explicando los tipos de opus } \\
\text { y las novedades constructivas (orden } \\
\text { toscano, partes arco). Al empezar con } \\
\text { el urbanismo, me permite acercarme al } \\
\text { caso de Roma para empezar a estudiar } \\
\text { los tipos de edificios }\end{array}$ & 30 \\
\hline Teoría & $\begin{array}{c}7 \\
\text { Video }\end{array}$ & $\begin{array}{l}\text { Vemos juntos el vídeo Rome reborn } \\
\text { (https://www.youtube.com/watch?time } \\
\text { continue=66\&v=f8haR208HiM) } \\
\text { Aprovecho para hablarles de la } \\
\text { importancia de las reconstrucciones } \\
\text { 3D para el conocimiento del pasado. } \\
\text { Aunque está en inglés, es muy visual y } \\
\text { yo les voy diciendo dónde se encuentran } \\
\text { los distintos edificios. }\end{array}$ & 10 \\
\hline
\end{tabular}




\begin{tabular}{|c|c|c|c|}
\hline Práctica & $\begin{array}{c}8 \\
\text { Investigación } \\
\text { del estudiante } \\
+ \\
\text { Reelaboración } \\
\text { de ideas }\end{array}$ & $\begin{array}{l}\text { Teniendo en cuenta la tarea asignada } \\
\text { dos semanas atrás de que cada alumno } \\
\text { se encargaba de documentarse acerca } \\
\text { de una tipología artística romana para } \\
\text { explicarlo a los compañeros, procedo a } \\
\text { otorgarle la palabra al alumno. } \\
\text { El orden se basará en los ejemplos de } \\
\text { mi power point. } \\
\text { Cada alumno explicará los rasgos del } \\
\text { tipo de edificio o de escultura escogido } \\
\text { y yo complementaré la explicación } \\
\text { mediante ejemplos de obras claveo. } \\
\text { Iremos intercalando algún ensayo de } \\
\text { cómo comentar una diapositiva en base } \\
\text { a lo que ya saben (El Panteón). } \\
\text { En el resto de la sesión abarcaremos } \\
\text { templos y mausoleos. }\end{array}$ & 15 \\
\hline
\end{tabular}

\begin{tabular}{|c|c|c|c|}
\hline \multicolumn{4}{|c|}{ SESIÓN 2. Arte romano (30/11) - 90 min. } \\
\hline $\begin{array}{c}\text { Modelo } \\
\text { metodológico } \\
\text { posible }\end{array}$ & Actividad & Descripción & $\begin{array}{c}\text { Tiempo } \\
\text { (min.) }\end{array}$ \\
\hline Práctica & $\begin{array}{c}8 \\
\text { Investigación } \\
\text { del estudiante } \\
+ \\
\text { Reelaboración } \\
\text { de ideas }\end{array}$ & $\begin{array}{l}\text { Continúa la misma actividad práctica. } \\
\text { Seguimos con las intervenciones de los } \\
\text { estudiantes guiadas y reforzadas por la } \\
\text { profesora. } \\
\text { Veremos teatros, anfiteatros, columnas } \\
\text { y arcos de triunfo, basílicas, termas, } \\
\text { acueductos, casas. } \\
\text { Me serviré de apoyos como el vídeo de } \\
\text { la villa Adriana: https://www.youtube. } \\
\text { com/watch?v=KlsxyuqdpEs } \\
\text { O el siguiente, sobre la Domus: } \\
\text { http s: / / w w w. yo u t u b e. c o m / } \\
\text { watch?v=04 2-qiWosE } \\
\text { Al terminar con todos los ejemplos, } \\
\text { pediré a los alumnos que me envien } \\
\text { por correo un resumen de lo que } \\
\text { me han contado, para colgarlo en la } \\
\text { Enseñanza Virtual. }\end{array}$ & 45 \\
\hline
\end{tabular}




\begin{tabular}{|c|c|c|c|}
\hline $\begin{array}{l}\text { Ideas de los } \\
\text { alumnos }\end{array}$ & $\begin{array}{l}9 \\
\text { Comparación } \\
\text { obras } \\
\text { romanas y } \\
\text { paleocristianas }\end{array}$ & $\begin{array}{l}\text { Llevaré impresas parejas de } \\
\text { imágenes de una obra romana y otra } \\
\text { paleocristiana equiparables: basílica, } \\
\text { sarcófago, mosaico y se las repartiré } \\
\text { por grupos de } 3 \text { o } 4 \text { personas, en } \\
\text { función del número de alumnos. } \\
\text { Tendrán unos minutos para hablar } \\
\text { entre ellos y decidir qué diferencias } \\
\text { existen entre las imágenes. Cada grupo } \\
\text { tendrá un portavoz que recogerá las } \\
\text { conclusiones por escrito y lo expondrá } \\
\text { ante el resto de la clase. Los otros } \\
\text { grupos podrán indicar su acuerdo o } \\
\text { desacuerdo }\end{array}$ & 20 \\
\hline $\begin{array}{l}\text { Reelaboración } \\
\text { / corrección de } \\
\text { ideas iniciales }\end{array}$ & $\begin{array}{l}10 \\
\text { Conclusión y } \\
\text { análisis de la } \\
\text { actividad }\end{array}$ & $\begin{array}{l}\text { Ante lo expuesto, ordenaré sus ideas } \\
\text { para encaminarlas hacia la respuesta } \\
\text { de la pregunta formulada al inicio } \\
\text { de este bloque, ¿cómo cambió el } \\
\text { cristianismo el arte romano? }\end{array}$ & 10 \\
\hline Teoría & $\begin{array}{c}11 \\
\text { Arte } \\
\text { paleocristiano. } \\
\text { Arquitectura }\end{array}$ & $\begin{array}{l}\text { Explicación teórica sobre el } \\
\text { arte paleocristiano. Novedades } \\
\text { arquitectónicas: catacumbas y } \\
\text { basílicas. }\end{array}$ & 15 \\
\hline
\end{tabular}

\begin{tabular}{|c|c|c|c|}
\hline \multicolumn{5}{|c|}{ SESIÓN 3. Arte Paleocristiano (31/10) -90 min. } \\
\hline $\begin{array}{c}\text { Modelo } \\
\text { metodológico } \\
\text { posible }\end{array}$ & Actividad & \multicolumn{1}{|c|}{ Descripción } & $\begin{array}{c}\text { Tiempo } \\
\text { (min.) }\end{array}$ \\
\hline Teoría & $\begin{array}{c}12 \\
\text { Arte } \\
\text { paleocristiano. } \\
\text { Artes figurativas }\end{array}$ & $\begin{array}{l}\text { Explicación teórica sobre el arte } \\
\text { paleocristiano. Nueva iconografía } \\
\text { religiosa: pintura mural, sarcófagos y } \\
\text { mosaicos. }\end{array}$ & 30 \\
\hline
\end{tabular}




\begin{tabular}{|c|c|c|c|}
\hline Práctica & $\begin{array}{c}13 \\
\text { Comentario } \\
\text { de obras } \\
\text { paleocristianas }\end{array}$ & $\begin{array}{l}\text { Práctica de comentario de diapositivas } \\
\text { a partir de lo estudiado. Como suelen } \\
\text { venir a clase un número reducido de } \\
\text { alumnos, por turnos e interviniendo } \\
\text { todos, tendrán que ir completando la } \\
\text { información de las obras comentadas. } \\
\text { Serán dos obras: planta de la basílica } \\
\text { de San Pedro de Roma y el sarcófago de } \\
\text { la Pasión. El objetivo es que aprendan } \\
\text { a aplicar los contenidos teóricos a } \\
\text { imágenes concretas. Es de especial } \\
\text { interés la práctica con el sarcófago, } \\
\text { donde tendrán que reconocer temas } \\
\text { iconográficos nuevos. }\end{array}$ & 35 \\
\hline $\begin{array}{l}\text { Reelaboración } \\
\text { / corrección de } \\
\text { ideas iniciales }\end{array}$ & $\begin{array}{c}14 \\
\text { Conclusión }\end{array}$ & $\begin{array}{l}\text { Reconduciendo algunas de las ideas } \\
\text { expuestas por los alumnos durante la } \\
\text { práctica y las actividades anteriores, } \\
\text { trataremos de enunciar una respuesta } \\
\text { para esa primera pregunta o problema } \\
\text { enunciado en la primera sesión }\end{array}$ & 10 \\
\hline \multicolumn{4}{|c|}{ PREGUNTA / PROBLEMA № 2: ¿Cómo influyó en el arte la división del Imperio romano? } \\
\hline $\begin{array}{l}\text { Ideas de los } \\
\text { alumnos }\end{array}$ & $\begin{array}{c}15 \\
\text { La división del } \\
\text { Imperio romano }\end{array}$ & $\begin{array}{l}\text { Tras plantear la segunda pregunta } \\
\text { de este bloque en alto, hacemos una } \\
\text { lluvia de ideas que voy anotando en la } \\
\text { pizarra. Es posible que esta vez ya sean } \\
\text { más precisas porque algunas de estas } \\
\text { cuestiones salieron en el vídeo de la } \\
\text { actividad no } 4 \text {. }\end{array}$ & 15 \\
\hline
\end{tabular}

SESIÓN 4. Arte Bizantino (06/11) - 90 min.

\begin{tabular}{|l|l|l|c|}
\hline \multicolumn{1}{|c|}{$\begin{array}{c}\text { Modelo } \\
\text { metodológico } \\
\text { posible }\end{array}$} & \multicolumn{1}{|c|}{ Actividad } & \multicolumn{1}{c|}{ Descripción } & $\begin{array}{c}\text { Tiempo } \\
\text { (min.) }\end{array}$ \\
\hline $\begin{array}{l}\text { Actividad de } \\
\text { contraste }\end{array}$ & $\begin{array}{l}16 \\
\text { Comparación de } \\
\text { imágenes }\end{array}$ & $\begin{array}{l}\text { Para completar las ideas surgidas } \\
\text { en la anterior actividad, proyecto } \\
\text { una fotografia de arte prerrománico } \\
\text { europeo y otra del período de Justiniano } \\
\text { (Bizantino). Por parejas, compararán las } \\
\text { imágenes para después poner en común } \\
\text { las conclusiones alcanzadas }\end{array}$ & 10 \\
\hline
\end{tabular}




\begin{tabular}{|c|c|c|c|}
\hline $\begin{array}{l}\text { Reelaboración } \\
\text { / corrección de } \\
\text { ideas iniciales }\end{array}$ & $\begin{array}{l}17 \\
\text { Conclusión y } \\
\text { análisis de la } \\
\text { actividad }\end{array}$ & $\begin{array}{l}\text { Ante lo expuesto, ordenaré sus ideas } \\
\text { para encaminarlas hacia la respuesta } \\
\text { de la pregunta formulada: ¿cómo } \\
\text { influyó en el arte la división del Imperio } \\
\text { romano? Valoraremos si la actividad } \\
\text { nos ha acercado a dar una respuesta, } \\
\text { posiblemente la vean algo más clara, } \\
\text { pero requerirá de más información }\end{array}$ & 10 \\
\hline Teoría & $\begin{array}{l}18 \\
\text { Contexto } \\
\text { histórico }\end{array}$ & $\begin{array}{l}\text { Explicación teórica sobre el contexto } \\
\text { histórico del arte bizantino y del arte } \\
\text { prerrománico partiendo de la división del } \\
\text { Imperio y destacando los casos paralelos } \\
\text { de personalidades como Justiniano } \\
\text { y Carlomagno, pese a la diversidad } \\
\text { cronológica. }\end{array}$ & 30 \\
\hline Práctica & $\begin{array}{l}19 \\
\text { Búsqueda de } \\
\text { respuesta }\end{array}$ & $\begin{array}{l}\text { Tras la explicación teórica } \\
\text { contextualizada, los alumnos redactarán } \\
\text { una respuesta breve a esa pregunta } \\
\text { inicial de manera individual, volviendo } \\
\text { en cierto modo a una de las preguntas } \\
\text { del cuestionario. Las recogeré para } \\
\text { comentarlas al final del CIMA, tras haber } \\
\text { abordado la pregunta no } 3 \text {. }\end{array}$ & 10 \\
\hline \multicolumn{4}{|c|}{$\begin{array}{c}\text { PREGUNTA / PROBLEMA № 3: ¿Qué elementos han perdurado desde Roma en el arte } \\
\text { Prerrománico y el Bizantino? }\end{array}$} \\
\hline $\begin{array}{l}\text { Ideas de los } \\
\text { alumnos }\end{array}$ & $\begin{array}{l}20 \\
\text { Introducción } \\
\text { arte bizantino }\end{array}$ & $\begin{array}{l}\text { Planteo la pregunta. ¿Qué sabemos del } \\
\text { arte bizantino? Ya han salido muchos } \\
\text { conceptos en estas sesiones, por lo que } \\
\text { deberían recordar nombres y ciudades } \\
\text { destacados. Realizaremos una lluvia } \\
\text { de ideas y reorientaré el discurso para } \\
\text { llevarnos a la ciudad de Constantinopla y } \\
\text { la arquitectura de Justiniano. }\end{array}$ & 10 \\
\hline $\begin{array}{l}\text { Actividad de } \\
\text { contraste }\end{array}$ & $\begin{array}{l}21 \\
\text { Novedades } \\
\text { arquitectónicas }\end{array}$ & $\begin{array}{l}\text { Para empezar a conocer una de las obras } \\
\text { más interesantes, proyectaré la planta } \\
\text { de Santa Sofía y tendrán que copiarla } \\
\text { a mano. Es una buena actividad de } \\
\text { reflexión sobre los volúmenes que les } \\
\text { permitirá entender esta estructura. }\end{array}$ & 10 \\
\hline $\begin{array}{l}\text { Reelaboración } \\
\text { / corrección de } \\
\text { ideas iniciales }\end{array}$ & $\begin{array}{l}22 \\
\text { Conclusión y } \\
\text { análisis de la } \\
\text { actividad }\end{array}$ & $\begin{array}{l}\text { Realizaré una síntesis de las respuestas } \\
\text { de la actividad } 20 \text {, enlazándolo con } \\
\text { la no } 21 \text { y remarcando qué elementos } \\
\text { provienen de Roma y cuáles son las } \\
\text { novedades en función de lo que hemos } \\
\text { visto en clase. }\end{array}$ & 10 \\
\hline
\end{tabular}




\begin{tabular}{|c|c|c|c|}
\hline \multicolumn{4}{|c|}{ SESIÓN 5. Arte Prerrománico (07/11) - 90 min. } \\
\hline $\begin{array}{c}\text { Modelo } \\
\text { metodológico } \\
\text { posible }\end{array}$ & Actividad & Descripción & $\begin{array}{l}\text { Tiempo } \\
\text { (min.) }\end{array}$ \\
\hline Teoría & $\begin{array}{c}23 \\
\text { Arte bizantino }\end{array}$ & $\begin{array}{l}\text { Explicación teórica desde Santa Sofía a } \\
\text { la expansión de la arquitectura bizantina. } \\
\text { También abordaré las artes figurativas, } \\
\text { planteando la continuidad con el } \\
\text { Paleocristiano, la importancia imperial, } \\
\text { crisis iconoclasta y aparición de una } \\
\text { iconografia pautada con ejemplos como } \\
\text { Dafni. }\end{array}$ & 35 \\
\hline Práctica & $\begin{array}{c}24 \\
\text { Comentario } \\
\text { de obras } \\
\text { bizantinas }\end{array}$ & $\begin{array}{l}\text { Práctica de comentario de diapositivas a } \\
\text { partir de lo estudiado. Como suelen venir a } \\
\text { clase un número reducido de alumnos, por } \\
\text { turnos e interviniendo todos, tendrán que } \\
\text { ir completando la información de las obras } \\
\text { comentadas. Serán dos obras: mosaicos de } \\
\text { San Vital de Rávena y mosaicos de Santa } \\
\text { Sofía y Dafni }\end{array}$ & 20 \\
\hline $\begin{array}{l}\text { Reelaboración } \\
\text { / corrección de } \\
\text { ideas iniciales }\end{array}$ & $\begin{array}{c}25 \\
\text { Conclusión }\end{array}$ & $\begin{array}{l}\text { Sintesis de las cuestiones principales del } \\
\text { arte bizantino. }\end{array}$ & 5 \\
\hline Teoría & $\begin{array}{c}25 \\
\text { Arte } \\
\text { Prerrománico: } \\
\text { carolingio }\end{array}$ & $\begin{array}{l}\text { Explicación teórica del arte carolingio. } \\
\text { Como ya se atendió al contexto en la } \\
\text { actividad 18, me centraré en la explicación } \\
\text { de cuestiones generales de arquitectura y } \\
\text { artes figurativas. }\end{array}$ & 30 \\
\hline
\end{tabular}

SESIÓN 6. Arte Prerrománico - Intro románico (13/11) - 90 min.

\begin{tabular}{|c|c|l|c|}
\hline $\begin{array}{c}\text { Modelo } \\
\text { metodológico } \\
\text { posible }\end{array}$ & Actividad & Descripción & $\begin{array}{c}\text { Tiempo } \\
\text { (min.) }\end{array}$ \\
\hline Práctica & $\begin{array}{c}26 \\
\text { Comentario } \\
\text { de obras } \\
\text { carolingias }\end{array}$ & $\begin{array}{l}\text { Práctica de comentario de diapositivas. } \\
\text { Como suele venir a clase un número } \\
\text { reducido de alumnos, por turnos tendrán } \\
\text { que ir completando la información de las } \\
\text { obras comentadas. Serán la capilla palatina } \\
\text { de Aquisgrán y los evangeliarios de Ebbon. }\end{array}$ & 15 \\
\hline
\end{tabular}

Jornadas de Formación e Innovación Docente del Profesorado | № 2 (2019) Esta obra se distribuye con la licencia Creative Commons Reconocimiento-NoComercial-SinObraDerivada Internacional (CC BY-NC-ND 4.0.) 


\begin{tabular}{|c|c|c|c|}
\hline $\begin{array}{c}\text { Ideas de los } \\
\text { alumnos }\end{array}$ & $\begin{array}{c}27 \\
\text { Introducción } \\
\text { arte } \\
\text { prerrománico }\end{array}$ & $\begin{array}{l}\text { Planteo la pregunta. ¿Qué sabemos del arte } \\
\text { prerrománico español? Realizaremos una } \\
\text { lluvia de ideas y reorientaré el discurso para } \\
\text { delimitar los grandes períodos y sus obras } \\
\text { más conocidas. }\end{array}$ & 10 \\
\hline $\begin{array}{l}\text { Actividad de } \\
\text { contraste } \\
+ \\
\text { Reelaboración } \\
\text { ideas }\end{array}$ & $\begin{array}{c}28 \\
\text { Arte visigodo } \\
\text { vs. Asturiano }\end{array}$ & $\begin{array}{l}\text { A partir del visionado de un par de vídeos } \\
\text { breves sobre el arte visigodo y el asturiano: } \\
\text { ht tps: / / w w w. y o u t u b e.co m / } \\
\text { watch?v=ZZ8U5eD43HE } \\
\text { ht t p s: / / w w w. y o u t u b e.c o m / } \\
\text { watch?v=2ZATYCFXN1g } \\
\text { Invitaré a los alumnos a plantear cuáles } \\
\text { consideran que son las diferencias y } \\
\text { similitudes. Tendrán } 5 \text { minutos para tratarlo } \\
\text { por parejas y lo pondremos en común para } \\
\text { reelaborar sus conclusiones y plantear las } \\
\text { principales cuestiones. }\end{array}$ & 20 \\
\hline Teoría & $\begin{array}{c}29 \\
\text { Introducción al } \\
\text { arte Románico }\end{array}$ & $\begin{array}{l}\text { Cerrando los períodos anteriores, haré una } \\
\text { breve explicación teórica que me lleve hacia } \\
\text { el momento inicial del románico, con un } \\
\text { contexto concreto y unos precedentes que } \\
\text { hemos visto en las sesiones anteriores. } \\
\text { Señalaré las que van a ser las principales } \\
\text { novedades en este período artístico en } \\
\text { los campos de la arquitectura, pintura y } \\
\text { escultura. }\end{array}$ & 20 \\
\hline Práctica & $\begin{array}{l}30 \\
\text { Comentario } \\
\text { comparativo } \\
\text { de imágenes } \\
\text { de arte } \\
\text { románico }\end{array}$ & $\begin{array}{l}\text { Para finalizar, proyectaré tres imágenes } \\
\text { representativas del Románico: la catedral } \\
\text { de Santiago de Compostela para ver la } \\
\text { arquitectura, San Lázaro de Autun para } \\
\text { ver escultura y las pinturas del ábside } \\
\text { San Clemente de Tahull para ver pintura. } \\
\text { Los alumnos harán un comentario de las } \\
\text { obras orientado a encontrar las novedades } \\
\text { respecto a lo que hemos visto, pero también } \\
\text { los vínculos con Roma, Bizancio y el mundo } \\
\text { prerrománico. }\end{array}$ & 15 \\
\hline Conclusión & Conclusión & $\begin{array}{l}\text { Volveré a proyectar la fotografia que hice a la } \\
\text { pizarra en la primera sesión con relación a la } \\
\text { pregunta inicial y comentaré los resultados } \\
\text { de la actividad no } 19 \text { para realizar un balance } \\
\text { de lo aprendido y de sus aportaciones, } \\
\text { resaltando las obras más representativas. }\end{array}$ & 10 \\
\hline
\end{tabular}




\section{Cuestionario inicial y final}

Si bien habitualmente suelo realizar una evaluación inicial al comenzar la docencia de cada asignatura, en la aplicación del ciclo de mejora elaboré un cuestionario inicial ajustado a los contenidos conceptuales que se iban a abordar. Mi objetivo era despertar el interés de los estudiantes por estos contenidos y evaluar su capacidad de razonamiento y conocimientos previos. Además, dicho cuestionario se contextualizó recreando una situación que motivara un pensamiento algo más alejado de lo estrictamente académico.

El cuestionario fue el siguiente:

Te han contratado como asesor experto en Ciencias Sociales para la producción de una serie que se desarrolla entre el Imperio romano y la Alta Edad Media. Para ir preparando la documentación histórica de la ambientación de los decorados, el director te pide que contestes a estas preguntas:

1. ¿Crees que la llegada del Cristianismo a Roma modificó el arte y la arquitectura romana? Si hubo cambios, ¿dónde se pueden encontrar? ¿cómo podríamos plasmarlos en la serie? [en relación con la pregunta/problema no 1 del mapa de contenidos]

2. ¿Influyó en el arte la división del Imperio Romano? ¿Cómo? [en relación con la pregunta/problema no 2 del mapa de contenidos]

3. ¿Qué diferencias hay entre el arte que se desarrolló durante la Alta Edad Media en Europa occidental y en Europa oriental? ¿Serían igual los decorados cuando la escena se desarrolla en Francia que los de Constantinopla? [en relación con la pregunta/ problema no 2 del mapa de contenidos]

4. ¿Qué elementos del arte romano crees que perduraron en el arte europeo de la Alta Edad Media? ¿en qué obras de arte podríamos encontrarlo con más facilidad? [en relación con la pregunta/ problema no 3 del mapa de contenidos] 


\section{Aplicación del CIMA}

\section{Descripción de las sesiones}

Me vi obligada a iniciar el CIMA con un día de retraso por cuestiones de temario. En el desarrollo de las primeras actividades a los estudiantes les sorprendió la pregunta inicial planteada respecto a las relaciones entre el arte romano y el románico, pero salieron algunas cuestiones interesantes. Algún alumno se quejaba de que les preguntaba las cosas antes de haberlas explicado, pero luego entraron de lleno al seguir preguntando de manera específica sobre el arte romano, ya que se sintieron algo más cómodos al pensar qué sabían de un período concreto. Me resultó agradable ver cómo se sorprendían ante ciertas cuestiones que desconocían o cómo valoraban a aquellos alumnos que sí tenían más conocimientos.

La asistencia fue variable, a la mayoría de las sesiones acudieron unos diez estudiantes, lo que permitía establecer un ambiente de diálogo bastante cercano y sin vergüenza por participar. Sin embargo, aquellos días en los que aumentaba el número resultaba más complicado, ya que eran alumnos con poco interés por participar e incluso que se perdian por su falta de asistencia a sesiones anteriores. Es uno de los problemas con los que me encuentro, oscila mucho la asistencia al ser una asignatura de 1o que se imparte de 18 a 19:30 al final de la semana.

Las actividades 7 y 8 fueron el núcleo del tema de arte romano y resultaron provechosas para los alumnos, pero me encontré con la dificultad en la número 8 de que unos cuantos estudiantes no habían realizado la tarea encargada para realizar en casa, por lo que tuve que explicar yo esas obras y, por lo tanto, la clase perdía algo de dinamismo con mis intervenciones. 
Por lo general, el resto del CIMA se desarrolló con normalidad, si bien fui acumulando ciertos retrasos y me vi obligada a suprimir ciertas actividades o acortar su duración. En todo caso, resultó muy interesante ver cómo funcionaban las comparaciones de imágenes y debates como la comparación de imágenes romanas y paleocristianas (actividad 9) o las prácticas de comentario de imágenes (actividades 13, 240 26).

En la última sesión, volvimos sobre algunos de los problemas que planteamos al inicio del CIMA y les ha resultado curioso reflexionar sobre lo que habían aprendido con relación a la primera sesión, en la que apuntamos las ideas iniciales en la pizarra, tras proyectar la fotografía que hice aquel día. Resulta satisfactorio ver cómo los estudiantes reconocen que se ha producido un aprendizaje y encuentran respuesta a las preguntas planteadas en la primera sesión.

\section{Evaluación del aprendizaje de los estudiantes (escaleras de aprendizaje)}

El análisis de los resultados de los cuestionarios inicial y final y su plasmación en las escaleras de aprendizaje revela unos resultados muy positivos. Se ha seguido la metodología desarrollada por Rivero y Porlán (73-91). En las cuatro preguntas se observa una mejora significativa en los conocimientos de los estudiantes. Solamente debo destacar que en la última pregunta no se ha dado un cambio tan sustancial. Por un lado, se apreciaba cierto cansancio en los estudiantes a la hora de rellenar la última respuesta, pero también se trata quizás de la pregunta que abarca una respuesta más transversal y, por lo tanto, compleja.

Imagen 6. Escalera de aprendizaje sobre la pregunta no4 del cuestionario. 
FSCAI FRA INICIAI Y FINAI SOBRFI A PRFGUNTAN 1 : ¿Crees que la llegada del Cristianismo a Roma modificó el artey la arquitectura romana? Si hubo cambios, ¿ dónde se pueden encontrar?

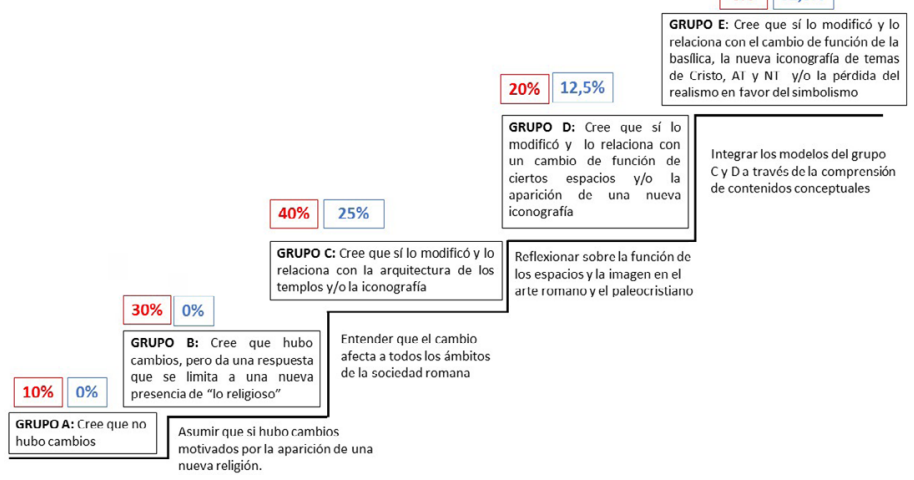

Imagen 3. Escalera de aprendizaje sobre la pregunta nำ1 del cuestionario.

ESCALERAINICIAL Y FINAL SOBRE LAPREGUNTANo 2: ¿̇Influyóen el arte la división del Imperio Romano? ¿Cómo?

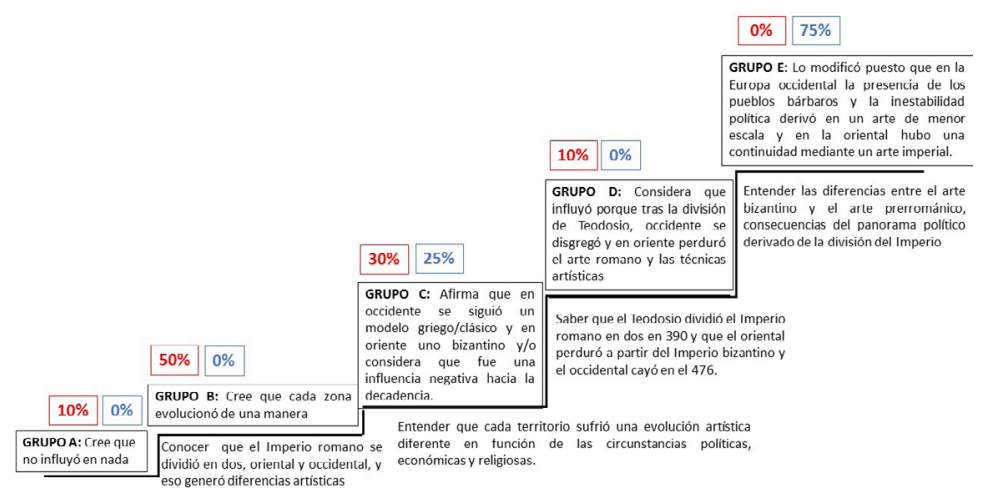

Imagen 4. Escalera de aprendizaje sobre la pregunta no2 del cuestionario.

ESCALERA INICIAL Y FINAL SOBRE LA PREGUNTA Nº 3: ¿Qué diferencias hay entre el arte que se desarrolló durante la Alta Edad Media en Europa occidental y en Europa oriental? ¿Serlan igual los decorados cuando la escena se desarrolla en Francia que los de Constantinopla?
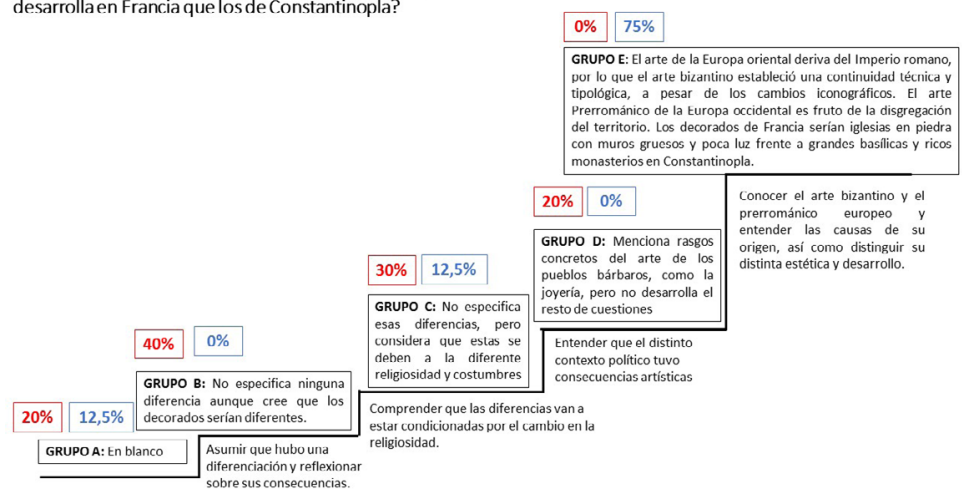

Imagen 5. Escalera de aprendizaje sobre la pregunta no3 del cuestionario.

Jornadas de Formación e Innovación Docente del Profesorado | № 2 (2019) Esta obra se distribuye con la licencia Creative Commons Reconocimiento-NoComercial-SinObraDerivada Internacional (CC BY-NC-ND 4.0.) 


\section{Cuadro de evolución por estudiante}

Al igual que ocurre con las escaleras de aprendizaje, el cuadro de evaluación por estudiante evidencia que prácticamente todos han mejorado con relación al cuestionario inicial, en algunos casos subiendo tres y cuatro escalones. Son unos resultados muy satisfactorios.

Tabla 2. Cuadro de evolución por estudiante

\begin{tabular}{|c|c|c|c|c|c|c|c|c|c|c|c|c|}
\hline Sujeto & \multicolumn{3}{|c|}{ Pregunta 1 } & \multicolumn{3}{|c|}{ Pregunta 2} & \multicolumn{3}{|c|}{ Pregunta 3 } & \multicolumn{3}{c|}{ Pregunta 4 } \\
\hline 1 & $\mathrm{D}$ & $\mathrm{E}$ & $\uparrow$ & $\mathrm{D}$ & $\mathrm{E}$ & $\uparrow$ & $\mathrm{D}$ & $\mathrm{E}$ & $\uparrow$ & $\mathrm{B}$ & $\mathrm{C}$ & $\uparrow$ \\
\hline 2 & $\mathrm{C}$ & $\mathrm{E}$ & $\uparrow \uparrow$ & $\mathrm{C}$ & $\mathrm{E}$ & $\uparrow \uparrow$ & $\mathrm{A}$ & $\mathrm{E}$ & $\uparrow \uparrow \uparrow \uparrow$ & $\mathrm{B}$ & $\mathrm{C}$ & $\uparrow$ \\
\hline 3 & $\mathrm{~B}$ & $\mathrm{E}$ & $\uparrow \uparrow \uparrow$ & $\mathrm{B}$ & $\mathrm{E}$ & $\uparrow \uparrow \uparrow$ & $\mathrm{C}$ & $\mathrm{E}$ & $\uparrow \uparrow$ & $\mathrm{B}$ & $\mathrm{C}$ & $\uparrow$ \\
\hline 4 & $\mathrm{D}$ & $\mathrm{E}$ & $\uparrow$ & $\mathrm{C}$ & $\mathrm{E}$ & $\uparrow \uparrow$ & $\mathrm{C}$ & $\mathrm{E}$ & $\uparrow \uparrow$ & $\mathrm{B}$ & $\mathrm{B}$ & $\leftrightarrow$ \\
\hline 5 & $\mathrm{~B}$ & $\mathrm{C}$ & $\uparrow$ & $\mathrm{B}$ & $\mathrm{C}$ & $\uparrow$ & $\mathrm{B}$ & $\mathrm{A}$ & $\downarrow$ & $\mathrm{B}$ & $\mathrm{C}$ & $\uparrow$ \\
\hline 6 & $\mathrm{C}$ & $\mathrm{E}$ & $\uparrow \uparrow$ & $\mathrm{C}$ & $\mathrm{E}$ & $\uparrow \uparrow$ & $\mathrm{B}$ & $\mathrm{E}$ & $\uparrow \uparrow \uparrow$ & $\mathrm{B}$ & $\mathrm{B}$ & $\leftrightarrow$ \\
\hline 7 & $\mathrm{~A}$ & $\mathrm{D}$ & $\uparrow \uparrow \uparrow \uparrow$ & $\mathrm{A}$ & $\mathrm{E}$ & $\uparrow \uparrow \uparrow \uparrow$ & $\mathrm{A}$ & $\mathrm{E}$ & $\uparrow \uparrow \uparrow \uparrow$ & $\mathrm{B}$ & $\mathrm{D}$ & $\uparrow \uparrow \uparrow$ \\
\hline 8 & $\mathrm{C}$ & $\mathrm{C}$ & $\leftrightarrow$ & $\mathrm{B}$ & $\mathrm{C}$ & $\uparrow$ & $\mathrm{C}$ & $\mathrm{C}$ & $\leftrightarrow$ & $\mathrm{B}$ & $\mathrm{B}$ & $\leftrightarrow$ \\
\hline 9 & $\mathrm{~B}$ & $*$ & $*$ & $\mathrm{~B}$ & $*$ & $*$ & $\mathrm{~B}$ & $*$ & $*$ & $\mathrm{~A}$ & $*$ & $*$ \\
\hline 10 & $\mathrm{~B}$ & $*$ & $*$ & $\mathrm{~B}$ & $*$ & $*$ & $\mathrm{~B}$ & $*$ & $*$ & $\mathrm{~A}$ & $*$ & $*$ \\
\hline
\end{tabular}

\section{Evaluación del CIMA}

\section{¿Qué ha funcionado bien? Cuestiones para mantener}

El Ciclo de Mejora ha sido muy satisfactorio, dado que he podido observar un incremento de la participación de los estudiantes, no solo en la descripción de imágenes, sino también en el razonamiento de procesos históricos y artísticos. Las actividades de debate o por parejas han funcionado muy bien, me ha resultado muy interesante observar cómo se interesaban por la materia, pese a no ser específicamente de su campo de estudio. Por otro lado, los cuestionarios iniciales y finales han demostrado ser herramientas de gran utilidad que mantendré en futuros ciclos.

Elementos que no han funcionado y cambios a introducir

Uno de los aspectos que ha dificultado el funcionamiento del CIMA ha sido el exceso de ambición a la hora de planificar la secuencia de actividades. He preparado 
demasiadas actividades, adjudicándoles un tiempo insuficiente en la planificación. Ello ha derivado en un considerable retraso en la fase de aplicación, impidiendo culminar el CIMA en el tiempo previsto. Considero que esta metodología es útil para mejorar el proceso de aprendizaje, pero el principal inconveniente es que su aplicación requiere el doble de tiempo en asignaturas con unos contenidos muy ajustados y prácticamente inabarcables incluso con una metodología de clase magistral.

Tampoco ha funcionado como esperaba el encargo de tareas a los alumnos para realizar en casa, probablemente debido a que no podía incluir los resultados de estas en la evaluación final. De cara a futuros ciclos, tendría que replantear la evaluación y posterior calificación de estas actividades para fomentar la participación.

\section{Aspectos de la experiencia a incorporar en la práctica docente habitual}

Me gustaría incorporar la utilización de cuestionarios iniciales y finales, al menos al inicio y fin de la asignatura y en algunos temas puntuales. También voy a procurar plantearme preguntas o ideas que encadenen los contenidos de las asignaturas, de modo que implique una cierta reflexión sobre los contenidos que voy a impartir y, sobre todo, cómo voy a impartirlos para que los estudiantes puedan seguir un hilo conductor. Algo que ya he incorporado es el abordaje de los contenidos desde las ideas previas de los alumnos ante una cuestión inicialmente planteada, ya que he comprobado que conlleva una mayor implicación por su parte en los temas tratados en clase.

\section{Principios didácticos argumentados}

Después de haber realizado el curso de innovación docente y tras la experiencia que ha supuesto la aplicación de este CIMA, he agrupado mis principios didácticos en cuatro bloques: aprendizaje de los alumnos, contenidos 
de enseñanza, metodología y evaluación. Estos principios no solo han guiado la experiencia de este CIMA, sino que han de permanecer en mi sistema didáctico en el futuro.

\section{Aprendizaje de los alumnos}

- Despertar el interés de los alumnos a partir de ideas o noticias que conecten con la actualidad.

- Otorgar prioridad a las ideas previas de los alumnos antes de abordar los problemas

- Interacción con los alumnos

\section{Contenidos de enseñanza}

- Trabajar los contenidos de cada unidad previamente para tener claro cuáles son los contenidos organizadores y distinguir aquellos prescindibles cuando no resulta posible abarcar el temario completo.

- Formular problemas o preguntas clave vinculadas a los contenidos.

- Reflexionar sobre los diferentes tipos de contenidos a incluir en las unidades, que los conceptuales no sean los únicos y se incluyan otros como procedimientos intelectuales o actitudes y valores.

Metodología:

- Aplicar un modelo metodológico basado en la reelaboración de las ideas de los estudiantes

- Las fases de dicho modelo serían: pregunta inicial, ideas del alumno, actividad de contraste, reelaboración de ideas iniciales, teoría, práctica y reelaboración de ideas iniciales.

- Diseñar una secuencia de actividades realista y acorde con el tiempo disponible y el necesario para la realización de cada actividad. 


\section{Evaluación:}

- Utilizar cuestionarios iniciales y finales, en la medida de lo posible, en las unidades de la asignatura.

- Incluir en la calificación final algunas de las actividades de la secuencia

- Categorizar las respuestas de los estudiantes por niveles y analizar los obstáculos de aprendizaje.

- Evaluar mi docencia mediante un cuestionario final por parte de los alumnos. 


\section{Referencias bibliográficas}

Alba, N. de y Porlán, R. (2017). La metodología de enseñanza. En R. Porlán (coord.), Enseñanza universitaria. Cómo mejorarla (pp. 37-54). Madrid: Morata.

Bain, K. (2007). Lo que hacen los mejores profesores de universidad. Valencia: Universidad de Valencia.

Claxton, G. (1987). Vivir y aprender. Psicología del desarrollo y del cambio en la vida cotidiana. Madrid: Alianza.

Escribano, A. y del Valle, A. (2008). El aprendizaje basado en problemas. Una propuesta metodológica en Educación Superior. Madrid: Narcea.

Finkel, D. (2008). Dar clase con la boca cerrada. Valencia: Universidad de Valencia.

Rivero, A. y Porlán, R. (2017). La evaluación en la enseñanza universitaria. En R. Porlán (coord.), Enseñanza Universitaria. Cómo mejorarla (pp. 77-91). Madrid: Morata.

VVAA (coord.) (2012). Innovación metodológica y docente en historia, arte y geografia. Santiago de Compostela: Universidade de Santiago de Compostela. 